\title{
Dynamic Quality Management System Mineral
}

\author{
Vladimir A. Makarova, \\ Evgeniy G. Malinovsky ${ }^{\text {a }}$, Igor I. Kazerb, \\ Georgii S. Kurchin ${ }^{a}$ and Alexander V. Efimov \\ ${ }^{a}$ Siberian Federal University \\ 79 Svobodny, Krasnoyarsk, 660041, Russia \\ ${ }^{b}$ LTD «Sorting Technology Radiometric Concentration» \\ 1/7 Televizornaya, Krasnoyarsk-41, 660028, Russia
}

The questions of increase work efficiency on the deposits of multicomponent ores due to the introduction of modern means and management methods. Highlight new ways of customer requirements to the quality of raw materials ore.

Keywords: ore quality, raw materials, management.

\section{Динамическая система управления качеством минерального сырья}

\author{
В.А. Макарова ${ }^{a}$ Е.Г. Малиновский ${ }^{a}$, \\ И.И. Кацер ${ }^{\sigma}$, Г.С. Курчин ${ }^{\mathrm{a}}$, А.В. Ефимов \\ ${ }^{a}$ Сибирский федеральный университет \\ Россия, 660041, Красноярск, пр. Свободный, 79 \\ ${ }^{6} \mathrm{OOO}$ «Техноросс» \\ Россия, 660028, Красноярск, ул. Телевизорная 1, стр. 7
}

Статья посвящена решению вопросов повышения эффективности отработки месторождений многокомпонентных руд за счет внедрения современных средств и способов управления качеством руд при подземной добыче. Освещчены новые пути обеспечения требований потребителей к качеству рудоминерального сырья.

Ключевые слова: руда, качество, сырье, управление.

(C) Siberian Federal University. All rights reserved

* Corresponding author E-mail address: VMakarov@sfu-kras.ru 


\section{Введение}

Снижение цен на минеральное сырьё и неблагоприятная рыночная конъюнктура на большинство типов товарной продукции горно-металлургического сектора является серьёзным вызовом для экспортно-ориентированных предприятий. При высокой волатильности на сырьевых рынках возникают новые риски в осуществлении долгосрочных инвестиционных программ, снижается их потенциальная эффективность, что требует оптимизации бизнес-модели, определённой корректировки перспективных планов развития производств, поиска новых источников и резервов для сохранения рентабельности на приемлемом уровне.

\section{Постановка проблемы}

Одними из главных источников повышения экономической эффективности работы горнометаллургических предприятий наряду с оптимизацией затрат служат повышение качества товарной продукции и сокращение её потерь на основных участках цепи: добыча минерального сырья (рудники) - переработка (обогатительные фабрики) - металлургический передел (заводы по производству металлов). Особенно актуально повышение качества продукции и сокращение потерь извлекаемых компонентов для предприятий, эксплуатирующих месторождения совместно залегающих разнотипных руд, отличающихся высокими показателями контрастности качественных характеристик.

Наиболее представительным объектом, где весь комплекс поставленных задач проявляется во всем многообразии, выступает Талнахский рудный узел, на котором десятки лет ведется отработка комплексных Талнахского и Октябрьского месторождений медно-никелевых руд. Совокупность сложнейших горно-геологических, горно-технических и технологических условий в сочетании с крайне изменчивыми качественными характеристиками минерального сырья определяет круг научно-практических задач по управлению качеством товарной продукции. Исходная качественная неоднородность минерального сырья на месторождениях предполагает резкое усложнение решаемых задач:

- обеспечить определенное среднее качество в каждой отдельной партии рудного сырья, поступающего потребителю;

- отклонение от этого среднего уровня не должно превышать допустимых значений;

- внутри каждой партии должна быть обеспечена однородность ее состава.

\section{Способ решения проблемы}

Решение поставленных задач реализуется через создание интеллектуальных динамических систем управления качеством продукции, интегрирующих возможности моделирования рудопотоков как объектов управления, начиная от пространственного размещения в недрах, планирования всех технологических производственных процессов, формирующих качество продукции, и оперативного управления по всей цепи основных переделов путем мониторинга и своевременного реагирования на знаковые отклонения. Подобные системы внедрены на многих крупных отечественных и зарубежных горно-металлургических предприятиях и доказали свою эффективность [1-3].

Для эффективной работы системы одновременно должны планироваться, определяться и контролироваться количественные и качественные характеристики формируемых рудопото-

$$
-127-
$$


ков, количество металла, добываемой и перерабатываемой рудной массы, объемы проходки, необходимые объемы закладки пустот и т.д.

В этой связи для реализации данной системы необходимо: создание цифровой блочной модели рудного тела с точной проекцией на него существующего состояния горных работ, включая отработанные участки и устройство системы контроля качества рудных потоков для получения полной информации о всех возможных направлениях очистной выемки. Кроме того, для обеспечения максимального эффекта потребуется регулярно проводить ревизию и совершенствование применяемых технологий ведения горных работ, создание автоматизированной системы принятия управляющих решений и строительство системы аккумулирующих емкостей, включая приемные бункеры околоствольных дворов, усреднительные склады и т.д. с известным качеством, позволяющие гибко реагировать на изменяющиеся условия и своевременно регулировать параметры составляющих элементов рудопотоков для обеспечения требуемых качественных характеристик.

Разработка такой динамической системы управления качеством минерального сырья - задача многофакторная и многогранная, включающая следующие обязательные элементы:

- цифровые модели месторождений, разработанные с использованием современных глобальных геоинформационных систем типа Micromine, Datamine и др. (рис. 1),

- определение оптимальной разведочной сети для участков сложного строения;

- оперативное опробование горных выработок с помощью переносных приборов (рентгенорадиометрических анализаторов), например X-MET 7000 компании SYNERCON или др. [4];

- перспективное и среднесрочное календарное планирование горных работ с многовариантной оптимизацией результатов по видам целевых функций (минимум приведенных затрат, максимум прибыли и т.д.) в виде автоматизированного создания календарных планов на основе блочных и полигональных моделей - математическая модель формирования качества рудопотоков на участке рудник - обогатительная фабрика. Наиболее сложная и ответственная часть системы, которая должна быть разработана под индивидуальные условия и учитывать уровень автоматизации всех процессов. Примеры успешного внедрения подобных математических моделей приведены в работах $[5,6]$;
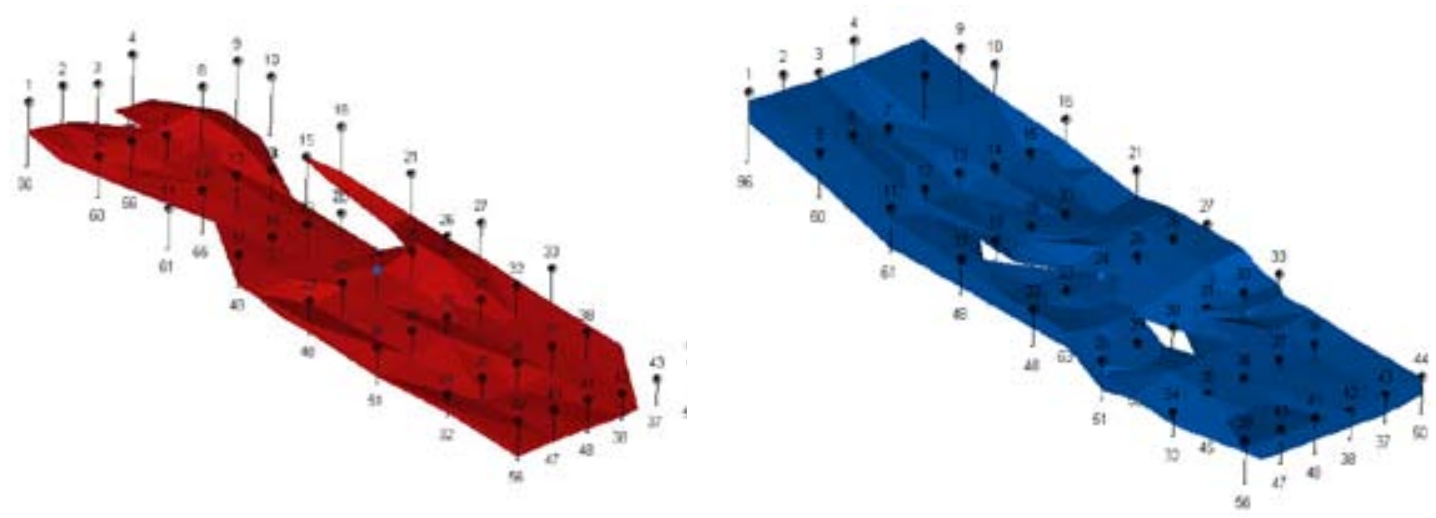

Рис. 1. Каркасные модели залежи богатых (красные) и вкрапленных (синие) руд 
- оперативное опробование крупных порций руды и крупнопорционная сортировка руд (КПС) в вагонетках (в перспективе - в ковшах ПДМ) на основе рудоконтролирующих станций (РКС);

- оперативный контроль и опробование руд в потоке (на конвейерных лентах) рудоконтролирующими станциями с возможностью сортировки руды крупными и мелкими порциями, например с помощью РКС-КМ компании «Технорос» (рис. 2);

- система инструментального контроля качественных характеристик перемещаемой руды в потоке в интерактивном режиме по разным направлениям отгрузки с возможностью ретроспективного анализа накопленных данных для выработки управляющих воздействий. Пример подобной системы внедрен в 2008 г. в ЗФ ПАО «ГМК «Норильский никель» и описан в работе [7];

- создание системы управляемых рудных складов для оперативной подшихтовки рудопотоков [5].

Исследования по разработке концепции динамической системы управления качеством руды были выполнены в рамках научно-исследовательской работы по гранту Красноярского краевого фонда поддержки научной и научно-технической деятельности на примере представительного рудника ЗФ ПАО «ГМК «Норильский никель» [8]. В работе были проанализированы состояние и возможности адаптации действующей на руднике системы контроля качества руды (СККР) в качестве основного элемента подобной системы.

В работе отмечено, что в условиях резкой изменчивости качественных характеристик исходного сырья и многоуровневой системы формирования рудопотоков значительно усложняются задачи оперативного контроля и управления. Возможности усреднения и сглаживания частотных и амплитудных колебаний качества должны быть определены и заложены на стадии проектирования технологических схем основных производственных процессов с привязкой к сменной производительности по отдельным наиболее значимым составляющим звеньям рудопотоков.

Разработка подобной системы - задача сложная и в большинстве аспектов инновационная. Однако реализация ее на горных предприятиях позволит обеспечить высокие технико-

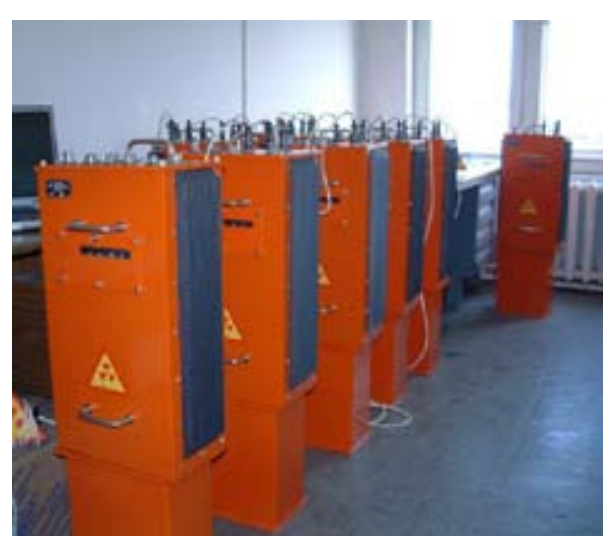

$a$

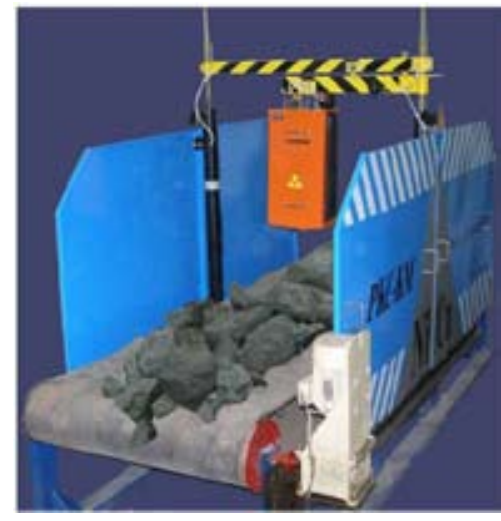

$\sigma$

Рис. 2. РКС-КМ : $a$ - заводские испытания РКС; $\sigma$ - сбор на ленточном конвейере

$$
-129-
$$


экономические показатели работы горно-добывающего и перерабатывающего производства, что достигается за счет снижения влияния человеческого фактора на технологические процессы, а также за счет получения достоверной и своевременной геологической информации и оперативного контроля содержания ценного компонента. При этом достигается существенный рост экономической эффективности всего горно-обогатительного производства, а также обеспечивается выполнение второго принципа рационального природопользования за счет повышения извлечения полезных ископаемых при добыче и переработке.

Подводя итог, можно сказать, что динамическая система управления и контроля качества добычи и переработки минерального сырья - это комплекс технологических, технических и организационных мероприятий по всей цепи «добыча - переработка», а также и во внутрирудничном звене, которая обеспечивает наибольший технико-экономический эффект всей цепи производственного комплекса. Естественно, что внедрение подобной многофакторной системы требует существенных средств не только в виде капитальных вложений, но и средств на поддержание работоспособности, обучение персонала, исследований и совершенствование системы. Опыт внедрения подобных систем показывает, что только при стабилизации качества руды и сокращении амплитудных и частотных характеристик содержаний эти затраты окупаются за счет повышения выхода концентрата и сквозного извлечения металлов на конечных переделах $[5,9,10]$.

Для реализации системы необходима разработка технических условий и стандартов предприятий на качество руд по звеньям формирования рудопотоков, а также стандартизация схем формирования рудопотоков и определения качества добытой руды на каждом уровне, включая опробование.

\section{Выводы}

1. Блочные цифровые модели рудных залежей позволяют перейти на качественно более высокий уровень достоверности учета баланса металлов по всей цепочке технологических процессов.

2. Применение пакетов специализированных программных продуктов для планирования горных работ дает возможность формировать рудопотоки с плановыми качественными характеристиками. Большинство современных ГГИС позволяют проводить стратегическое и оперативное планирование отработки месторождения с подготовкой планов разной степени срочности, поэтому наиболее эффективным будет принятие одной из них для внедрения и обучения специалистов разных профилей горной направленности работе в единой либо в нескольких взаимноинтегрированных системах, что позволит создать единую современную систему управления, контроля и планирования горных работ.

3. Оперативное управление и контроль за соблюдением качественных характеристик поставляемого потребителям минерального сырья сокращают размах колебаний средних значений содержания металлов.

4. Стабилизация качества и повышение однородности содержания в рудном сырье повышают извлечение полезных компонентов при переработке, что положительно скажется на общей экономической эффективности сквозного извлечения металлов от руды в недрах до готовой продукции. 
5. Ведение оперативного количественного баланса металлов по всем звеньям цепи от забоя до приемных бункеров ОФ с возможностью гибкого реагирования на нештатные производственные ситуации.

\section{Список литературы}

[1] Орлов О.И., Дударев А.Г. Технология усреднения качества руды в ОАО «Карельский окатыш». Горный журнал, 2012, 1S [Orlov O.I., Dudarev A.G. The technology of averaging the quality ores by JSC «Karelian pellet», Gornyi Zhurnal, 2012, 1S (in Russian)]

[2] Мукушаева А.С. Управление качеством руды в процессе добычи и обогащения. Обогащение руд. 2010, 5, 6-8 [Mukusheva A.S. Quality management ore in the mining process and beneficiation, Obogashchenie rud, 2010, 5, 6-8 (in Russian)]

[3] Кожиев Х.Х., Хугаева Г.Н. Способы управления качеством руд при подземной добыче, ГИАБ, 2010, 210-214 [Kozhiev Kh.Kh., Khugaeva G.N. Methods of quality management ore in underground mining, Mining Informational and Analytical Bulletin, 2010, 210-214 (in Russian)]

[4] X-MET 7000 портативный анализатор металлов и сплавов: техн. информация. М.: ООО «Синеркон», 2015 [X-MET 7000 portable analyzer of metals and alloys: technical. information TM SYNERCON, Moscow, 2015], available at: http://www.synercon.ru.

[5] Каранин Д., Нагарев А., Шишкин А. Система контроля качества руды на горнообогатительной фабрике. Современные технологии автоматизащии, 2010, 1, 36-39 [Karanin D., Nagarev A., Shishkin A. The quality control system of ore at an ore-dressing plant, Contemporary Technologies in Automation, 2010, 1, 36-39 (in Russian)]

[6] Кожиев, Х.Х., Ломоносов Г.Г. Рудничные системы управления качеством минерального сырья, 2-е изд., стер. М.: Изд-во МГГУ, 2008, 292 с. [Kozhiev Kh.Kh., Lomonosov G.G. Mining system of quality management of mineral raw materials, 2 ed., Moscow State Mining University, 2008, 292 p. (in Russian)]

[7] Павлишин Д.Н., Шумилов П.А., Терещенко С.В. Разработка программного модуля «Управление качеством руды» [Pavlishin D.N., Shumilov P.A., Tereshchenko S.V. The development of the software module "Management of Ore Quality"], available at: http://www.arcticsu.ru/system/ files/cdo/pavlishinadn.pdf

[8] Ефименко С.А. Новая концепция технического перевооружения рудников Жезказганского комплекса компании Kazakhmys LLC с использованием ядерно-геофизических технологий. Журнал СФУ. Техника и технологии, 2008 1(2), 117-125 [Yefimenko, S.A. The New Concept of Mine Modernisation on the Zhezkazgan Complex, Kazakhmys LLC Company, Using Nuclear Geophysical Technologies, J. Sib. Fed. Univ. Eng. technol.,2008 1(2), 117-125 (in Russian)]

[9] Создание динамической системы управления и контроля качества добычи и переработки минерального сырья на основе моделирования месторождений и управления рудопотоками: отчет о НИР, Красноярск, 2009, 102 с. [The establishment of dynamic management system and quality control of extraction and processing of mineral raw materials on the basis of modeling of the fields and management of the ore-stream: a report on research, Krasnoyarsk, 2009, 102 p. (in Russian)] 
[10] Литвиненко В.В., Туртыгина Н.А. Технико-экономическая эффективность от стабилизации качества руды. ГИАБ, 2008 [Litvinenko V.V., Turtygina N.A. Technical and Economic Efficiency of Stabilization of Ore Quality, Mining Informational and Analytical Bulletin, 2008 (in Russian)] 